\title{
Universiteit
}

Leiden

The Netherlands

\section{Definition of urinary tract infection in nursing homes}

Achterberg, W.P.; Went, P.B.M.

\section{Citation}

Achterberg, W. P., \& Went, P. B. M. (2012). Definition of urinary tract infection in nursing homes, 80(1), 99-100. doi:10.1016/j.jhin.2011.08.026

Version: $\quad$ Not Applicable (or Unknown)

License: $\quad$ Leiden University Non-exclusive license

Downloaded from: https://hdl.handle.net/1887/116908

Note: To cite this publication please use the final published version (if applicable). 
Table I

Effect of air disinfection (AD) unit on microbial air contamination in a vascular wound outpatient clinic

\begin{tabular}{ccc}
\hline Sample day & $\begin{array}{c}\text { Mean TVC } \pm \text { SD } \\
\text { (range) }\end{array}$ & $\begin{array}{c}\text { Mean cfu/L } \pm \text { SD } \\
\text { (range) }\end{array}$ \\
\hline \multicolumn{3}{l}{ Baseline/preliminary sampling } \\
1 & $20 \pm 33(0-140)$ & $148 \pm 228(156-770)$ \\
2 & $17 \pm 29(0-95)$ & $284 \pm 718(102-2518)$ \\
3 & $16 \pm 25(0-95)$ & $517 \pm 958(140-2518)$ \\
4 & $11 \pm 19(0-71)$ & $285 \pm 718(102-2518)$ \\
Without AD unit & & \\
5 & $28 \pm 37(0-150)$ & $319 \pm 708(300-2518)$ \\
6 & $11 \pm 19(0-71)$ & $300 \pm 712(102-2518)$ \\
7 & $17 \pm 26(0-100)$ & $503 \pm 949(300-2518)$ \\
8 & $16 \pm 33(0-140)$ & $544 \pm 945(140-2518)$ \\
With AD unit & & \\
9 & $12 \pm 19(0-71)$ & $300 \pm 712(102-2518)$ \\
10 & $11 \pm 18(0-68)$ & $302 \pm 711(170-2518)$ \\
11 & $11 \pm 20(0-66)$ & $332 \pm 714(298-2518)$ \\
12 & $16 \pm 27(0-95)$ & $477 \pm 958(140-2518)$ \\
\hline
\end{tabular}

TVC, total viable counts; cfu/L, colony-forming units per $L$ (value corrected according air sampler manufacturer's table).

\section{Conflict of interest statement}

H.H. has had recent research collaborations with Steris Corporation, 3M, Inov8 Science, Pfizer and Cepheid. He has also recently received lecture and other fees from $3 \mathrm{M}$, Novartis and Astellas.

\section{Funding sources}

The machines for this study were supplied by Inov8, free of charge. D.O.B. has received research funding and support to attend conferences from Pfizer.

\section{References}

1. Eames I, Tang JW, Li Y, Wilson P. Airborne transmission of disease in hospitals. J R Soc Interface 2009;6:S697-S702.

2. Datta R, Huang SS. Risk and death due to methicillin-resistant Staphylococcus aureus in long-term carriers. Clin Infect Dis 2008;47:176-181.

3. Wong V, Staniforth K, Boswell TC. Environmental contamination and airborne microbial counts: a role for hydroxyl radical disinfection units? J Hosp Infect 2011;78:194-199.

4. O'Donoghue L. HPA report no. 38/07: an evaluation of a novel air disinfection system against microbial aerosols. London: Health Protection Agency; 2007. pp. 1-19.

D. O’Brien* N. Stevens

D. Fitzgerald-Hughes

H. Humphreys

Departments of Microbiology, The Royal College of Surgeons in Ireland and Beaumont Hospital, RCSI Education and Research Centre, Beaumont Hospital, Dublin, Ireland

* Corresponding author. Address: Departments of Microbiology, The Royal College of Surgeons in Ireland and Beaumont Hospital, RCSI Education and Research Centre, Beaumont Hospital, PO Box 9063, Dublin 9, Ireland. E-mail address: de.obrien@svuh.ie (D. O’Brien).
Accepted by J.A. Child Available online 25 November 2011

(c) 2011 The Healthcare Infection Society. Published by Elsevier Ltd. All rights reserved. doi:10.1016/j.jhin.2011.08.018

\section{Definition of urinary tract infection in nursing homes}

Madam,

We have read the article by Eikelenboom-Boskamp et al. with great interest. ${ }^{1}$

Publications of prevalence rates of infections in long term care facilities are very important, especially if they report longitudinal data. There is, however, one methodological issue that needs attention. Eikelenboom-Boskamp et al. state that the definition of urinary tract infection (UTI) employed was based on the UTI guideline by the Dutch Association of Elderly Care Physicians, whereas the guideline's definition is different from that used by the authors. ${ }^{2}$

The guideline states that there must be: (i) symptoms or signs (related directly to the urinary tract or aspecific symptoms); (ii) bacteriuria; and (iii) some sign of inflammation.

The definition used in the study by Eikelenboom-Boskamp et al. used the following definition:

1. No other recognised cause and antibiotics commenced (unless antibiotics are not desirable, e.g. a terminally ill resident) and physician diagnosis of a urinary tract infection in resident with signs or symptoms (with or without an indwelling urinary catheter) and positive dipstick for leucocyte esterase and/or nitrate. 2 . In the absence of signs or symptoms: positive dipstick for leucocyte esterase and/or nitrate or positive urine culture.

The estimated prevalence may therefore have been too high, because of the bias of asymptomatic bacteriuria. We would like to stress the importance of using a definition in which symptoms, bacteriuria and signs of infection are incorporated, in order to reduce the use of antibiotics for asymptomatic bacteriuria.

\section{Conflict of interest statement}

None declared.

Funding sources

None.

\section{References}

1. Eikelenboom-Boskamp A, Cox-Claessens JH, Boom-Poels PG, Drabbe Ml, Koopmans RT, Voss A. Three-year prevalence of healthcare-associated infections in Dutch nursing homes. J Hosp Infect 2011;78:59-62.

2. Went $\mathrm{P}$, Achterberg $\mathrm{W}$, Bruggink $\mathrm{R}$, et al. NVVA richtlijn urineweginfecties. NUVA, Utrecht. mei 2006 [in Dutch.].

W.P. Achterberg* P.B.M. Went 
Department of Public Health and Primary Care, Leiden University Medical Center, Leiden, The Netherlands

* Corresponding author. Address: Department of Public Health and Primary care, Leiden University Medical Center, Hippocratespad 21, Postzone V0-P, Room V6-28, Post box 9600, 2300 RC Leiden, The Netherlands. Tel.: +31 (0) 71 5268412/71 5268427; fax: +31 (0) 715268259 . E-mail address: w.p.achterberg@lumc.nl (W.P. Achterberg).

Accepted by J.A. Child Available online 25 November 2011

(C) 2011 The Healthcare Infection Society. Published by Elsevier Ltd. All rights reserved.

doi:10.1016/j.jhin.2011.08.026

\section{Dissemination of extended-spectrum $\beta$-lactamase-producing Escherichia coli at home: a potential occupational hazard for healthcare workers?}

\section{Madam,}

Extended-spectrum $\beta$-lactamases (ESBLs) in Gram-negative pathogens are increasingly prevalent in Ireland. ${ }^{1}$ They present significant therapeutic and infection control challenges. While much of the literature has focused on the dissemination of ESBLproducing organisms to patients in different clinical and epidemiological settings, several reports have also investigated the transmission of such strains among household members of patients carrying them. ${ }^{2,3}$ However, the potential risk of occupational exposure of healthcare workers to ESBL-producing bacteria and of onward transmission to household contacts has not received significant attention. We report a case of ESBLproducing $E$. coli bloodstream infection in a healthcare worker associated with subsequent isolation of an indistinguishable strain from one causing a urinary tract infection in his spouse.

A 61-year-old medical doctor practising in a tertiary care hospital was admitted to hospital for investigation of jaundice and weight loss. Endoscopic retrograde cholangiopancreatography was performed and within hours the patient developed pyrexia and rigors. There was no recent history of hospitalization or antimicrobial chemotherapy. A clinical diagnosis of ascending cholangitis was made and he was commenced on intravenous piperacillin-tazobactam $4.5 \mathrm{~g}$ three times daily. Blood cultures yielded a pure growth of $E$. coli. The results of antimicrobial susceptibility testing with the Vitek-2 automated susceptibility test system (bioMérieux, Basingstoke, Hampshire, UK) are as shown in Table I. On day 4, in view of slow clinical progress and susceptibility test results of the $E$. coli bloodstream isolate, treatment was changed to meropenem $1 \mathrm{~g}$ three times daily. He received meropenem for 10 days, and was discharged following prompt resolution of pyrexia and an uneventful recovery.

Six weeks later, the 59-year-old spouse of the healthcare professional (a non-healthcare worker) presented to the same hospital with clinical features of acute pyelonephritis against a background history of chronic pelvo-ureteric junction obstruction. She informed the team of her husband's recent medical history. The admitting medical team commenced her on piperacillin-tazobactam $4.5 \mathrm{~g}$ three times daily pending further investigations. With no clinical improvement after $48 \mathrm{~h}$, treatment was empirically changed to intravenous meropenem $1 \mathrm{~g}$ three times daily on the advice of the clinical microbiologist. A renal ultrasound investigation revealed gross hydronephrosis of the right kidney. A percutaneously inserted nephrostomy tube drained $20 \mathrm{~mL}$ of pus, which yielded a pure growth of $E$. coli with an antibiogram indistinguishable from

Table I

Antimicrobial susceptibility, beta-lactamase and plasmid profiles of the Escherichia coli strains of the two patients

\begin{tabular}{|c|c|c|}
\hline $\begin{array}{l}\text { Antimicrobial susceptibility, } \\
\text { beta-lactamase and plasmid profiles }\end{array}$ & E. coli of index patient & E. coli of index patient's spouse \\
\hline Source & Blood & Intra-renal pus \\
\hline \multicolumn{3}{|l|}{ MICs (mg/L) of antimicrobial agents } \\
\hline Amoxicillin & $\geq 32$ & $\geq 32$ \\
\hline Amoxicillin-clavulanic acid & $\geq 32^{a}$ & $\geq 32^{a}$ \\
\hline Piperacillin & $\geq 128$ & $\geq 128$ \\
\hline Piperacillin-tazobactam & $32^{\mathrm{b}}$ & $16^{\mathrm{b}}$ \\
\hline Cefotaxime & $\geq 64$ & $\geq 64$ \\
\hline Ceftazidime & 16 & 8 \\
\hline Meropenem & $\leq 0.25$ & $\leq 0.25$ \\
\hline Gentamicin & $\geq 16$ & $\geq 16$ \\
\hline Amikacin & 16 & 16 \\
\hline Tobramycin & $\geq 16$ & $\geq 16$ \\
\hline Ciprofloxacin & $\geq 4$ & $\geq 4$ \\
\hline Trimethoprim-sulfamethoxazole & $\geq 320^{c}$ & $\geq 320^{c}$ \\
\hline$\beta$-Lactamases & CTX-M-15, TEM-1, OXA-1 & CTX-M-15, TEM-1, OXA-1 \\
\hline Plasmid profiles (kb) & $2.6,4,60,100$ & $2.6,4,60,100$ \\
\hline
\end{tabular}

MICs, minimal inhibitory concentrations.

\footnotetext{
a Amoxicillin component.

b Piperacillin component.

c Sulfamethoxazole component.
} 